\title{
HYDRAULIC RELATIONS AND WATER USE OF MEDITERRANEAN ORNAMENTAL SHRUBS IN CONTAINERS
}

\author{
Paolo ZUCCARINI ${ }^{1 *}$, Alejandro GALINDO ${ }^{2}$, Arturo TORRECILLAS $^{3}$, \\ Alberto PARDOSSI ${ }^{4}$, Brent CLOTHIER ${ }^{5}$ \\ ${ }^{1}$ CSIC, Global Ecology Unit CREAF-CEAB-UAB, Cerdanyola del Vallès, 08193 Catalonia, Spain \\ ${ }^{2}$ Department of Agroforestry Science, Universidad de Sevilla, 41013, Sevilla, Spain \\ ${ }^{3}$ Department of Plant Sciencies and Microbiology, Escuela Politécnica Superior de Orihuela, 03312, Alicante, Spain \\ ${ }^{4}$ Dipartimento di Scienze Agrarie, Alimentari e Agroambientali. University of Pisa, Pisa, Italy \\ ${ }^{5}$ Plant \& Food Research, Batchelar Road, Palmerston North 4442, New Zealand
}

Received: February 2020; Accepted: May 2020

\begin{abstract}
A detailed, species-specific comprehension of plant water behavior can be a central tool to improve water management in nursery production and irrigated landscapes. Potted plants of Nerium oleander, Pittosporum tobira, and Ligustrum japonicum 'Texanum' were exposed to controlled increasing drought conditions in greenhouse. Water use, gas exchange, and foliar thermoregulation were monitored along the trial. $N$. oleander showed the most efficient response to increasing water stress, maintaining high levels of gas exchange and evapotranspiration rate during the whole trial, whereas L. japonicum emerged as the most sensitive species, with a significant drop in physiological performances already from the second day. The more aggressive water behavior of $N$. oleander can be compared to the one of anisohydric plants, whereas L. japonicum displays an isohydric strategy. P. tobira showed intermediate characteristics between the two other species. This work comes to provide useful tools for the management of irrigation in plant nursery and for decision making in the use of ornamental shrubs for landscape applications.
\end{abstract}

Key words: gas exchange, hydric behavior, Mediterranean shrubs, water stress, water use

\begin{abstract}
Abbreviations: ET - evapotranspiration $(\mathrm{mm}) ; \mathbf{E T E}_{\mathbf{h}}-$ hourly evapotranspiration $\left(\mathrm{mm} \cdot \mathrm{h}^{-1}\right)$; $\mathbf{g s}$ - leaf stomatal conductance $\left(\mathrm{mol} \cdot \mathrm{m}^{-2} \cdot \mathrm{s}^{-1}\right)\left(\right.$ where $\mathbf{g s}_{\text {por }}=$ measured values and $\mathbf{g s}_{\mathbf{c a l}}=$ calculated values $) ; \mathbf{R G}-$ incident radiation $\left(\mathrm{MJ} \cdot \mathrm{m}^{-2} \cdot \mathrm{h}^{-1}\right) ;$ VPD - vapor pressure deficit $(\mathrm{kPa}) ;$ C.C. - container capacity $(\%) ; \mathrm{ET} / \mathrm{RG}\left(\mathrm{g} \cdot \mathrm{MJ}^{-1}\right)$
\end{abstract}

\section{INTRODUCTION}

Agriculture is the largest consumer of water globally, accounting for $70 \%$ of total withdrawals (UNEP 2007) but is limited by shortfalls in water quality and quantity (Hoekstra \& Chapagain 2007; Postel 2000). Limited water supplies, and continued population growth, demand more efficient water management (Sample 2009; IEEE 2010).
Demand for ornamental plants has been significantly increasing during the past decade (Incrocci et al. 2014) for purposes of urban decoration and gardening and also for environmental restoration and bioremediation (Denys et al. 2006; Sun et al. 2011). This fact, in combination with the abovementioned aspects, implies a double challenge for the plant nursery industry, which will have to increase its production (Savé et al. 1999) and, at the 
same time, reduce its water inputs through resource optimization.

Historically, one of the most important innovations in the nursery sector has been the switch from mineral soil to soilless cultivation in plastic containers filled with inert substrate that simplified the task of controlling and optimizing water inputs (Di Lorenzo et al. 2013). However, nursery stock in organic substrates are still over-irrigated and leach slow-release fertilizers (Ristvey et al. 2004), which wastes water and pollutes waterways (StewartWade 2011).

Appropriate nursery irrigation requires scheduling in order to provide plants with the adequate amount of water at the correct time. Such scheduling can be based on (1) climate - the evaporative demand and its effects on soil-water balance; see Allen et al. (1998); (2) substrate - its water-holding properties, and the monitoring of substrate moisture $(\Theta)$ status; (3) plant water use traits - centered on the relationship between crop water stress and soil water deficit; see Jones (2004) or on their integration. In particular, mathematical modeling is a way to combine the abovementioned strategies with an integrated approach (Gu et al. 2020).

Although microclimate and substrate waterholding properties are quantifiable, plant water use traits are complex and vary among species and cultivars (Knox 1989; Schuch \& Burger 1997; Mugnai et al. 1999). Few guidelines are nowadays available for the planning and management of irrigation, and in the reality of nursery production, these topics are addressed most of the times based on the empirical observations more than on modeling (Di Lorenzo et al. 2013).

The aim of the present work was to study the behavior of three ornamental species in containers under increasing water stress, through a continuous monitoring of their ecophysiological responses. The final aim is to highlight differences among the studied species and classify them based on their strategies of stress response, in order to optimize water investments and nursery practices according to the plant type.

\section{MATERIALS AND METHODS}

\section{Experimental design}

Three common ornamental shrubs were chosen for this experiment: Nerium oleander L., Pittosporum tobira Thunb., and Ligustrum japonicum Thunb. 'Texanum'.

Plants, 14 months of age, were cultivated in plastic containers, with a $18-\mathrm{cm}$ top diameter, $6.5 \mathrm{dm}^{3}$ of volume, filled with a peat-pumice $(1: 1, \mathrm{v}: \mathrm{v})$ mixture, and placed in a non-heated iron/PVC greenhouse, whose coordinates were $43^{\circ} 70^{\prime} 43^{\prime \prime}$ North and $10^{\circ} 42^{\prime} 75^{\prime \prime}$ West; the period of the year was September.

A five-day dry-down cycle versus control was performed. Plants were watered daily by hand as a partial or total root zone refilling of water lost through evapotranspiration. Control plants were kept at the $100 \%$ of container capacity during the whole trial, whereas stressed plants were subjected to $90 \%, 80 \%, 70 \%$, and $60 \%$ of container capacity along the study period. Six replicates were used for each species and water treatment combination. The entire cycle was replicated three times, subsequently, on new specimens not previously subjected to drought stress.

\section{Measurements}

Air temperature $(\mathrm{T})$ and relative humidity $(\mathrm{RH})$ in the greenhouse were constantly monitored with a data logger FT-105/RF-LCD (Econorma ${ }^{\circledR}$, Trento, Italy). For each day of trial, the average value of three measurements corresponding to the hours of the day with highest radiation (11:30, 12:30, and 13:30) was calculated. Vapor pressure deficit (VPD) was calculated from $\mathrm{T}$ and $\mathrm{RH}$ for the same hours.

Incident radiation was measured using a pyranometer (Delta-T Devices, Burwell, England) connected to the data logger. Global incident radiation during the period of measurements of the physiological parameters was calculated daily as the difference between the cumulated radiation values at 14:00 and 11:00. Climatic data are presented in Figure 1. 


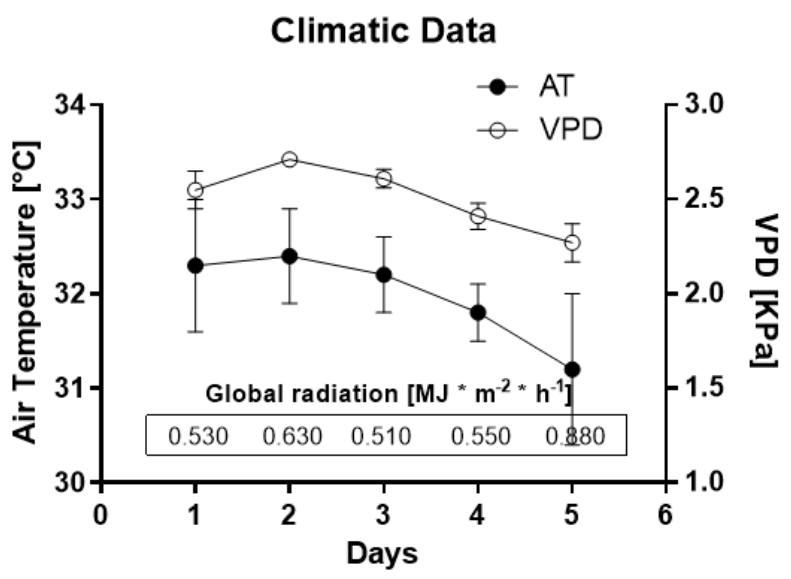

Fig. 1. Trend of climatic data during the days of experiment: Temperature (closed circles), vapor pressure deficit (VPD, open circles), and global radiation (RG) are shown. Error bars for each average value of temperature and VPD come from 3 measurements, taken at the hours of the day with highest radiation $(11: 30,12: 30$, and 13:30). RG values refer to the interval 11:30-13:30

Water use was gravimetrically determined daily as the difference in weight between 14:00 (end of measurements) and 11:00 (beginning of measurements). Hourly evapotranspiration was then calculated.

Containers were weighted again every day at sunset in order to calculate the amount of water needed for the reintegration up to water content planned for the next day. A water retention curve was calculated for the substrate used in the experiment through tensiometric cassette and Richard's plates according to the Piemonte Region analytical methods (ARPA 1992; Cassel \& Klute 1986). The relationships between container capacity and substrate water tension are given in Table 1.

Table 1. Substrate water tension (SWT) versus percentage of container capacity for the three investigated species

\begin{tabular}{cccccc}
\hline \multicolumn{2}{c}{ N. oleander } & \multicolumn{2}{c}{ L. japonicum } & \multicolumn{2}{c}{ P. tobira } \\
\hline SWT & \% C.C. & SWT & \% C.C. & SWT & \% C.C. \\
\hline 8 & 100 & 18 & 100 & 23 & 100 \\
26 & 89.5 & 35 & 90.7 & 41 & 90.7 \\
46 & 78.8 & 41 & 85.6 & 65 & 85.6 \\
78 & 69.6 & 65 & 76.1 & 90 & 76.1 \\
117 & 59.8 & 101 & 65.3 & 135 & 65.3 \\
\hline
\end{tabular}

Leaf stomatal conductance was measured with a transit-time diffusion porometer (Mk3, Delta-T Devices, Burwell, England) and then transformed, for each species, into relative values $\left(\mathrm{gS}_{\mathrm{rel}}=\left[\left(\mathrm{gs}_{\mathrm{i}} / \mathrm{gs}_{\max }\right) \cdot 100\right]\right.$, where $\mathrm{gs}_{\mathrm{i}}$ was one random measurement and $\mathrm{gs}_{\max }$ was the maximum value recorded for a species.

Foliar temperature was measured through a portable infrared thermometer (Cyclops Compac 3 Minolta/Land, Sheffield, UK), assuming an emissivity $(\varepsilon)$ of 0.93 for plant tissues (Styles et al. 2002). Both leaf conductance and temperature were measured daily on two marked leaves for each plant in the interval between 11:30 and 13:30.

At the end of the trial, the leaf area was measured for each plant with a digital planimeter $(\Delta T$ Area Meter Mk2, Delta-T Devices, Burwell, England).

\section{Statistical analyses}

Data were subjected to analysis of variance (ANOVA) using SAS version 9.1 (SAS Institute, USA). 3-way ANOVA was performed with species $\times$ day (container water capacity) $\times$ cycle as descriptors. The significance of differences between means was determined using Duncan's multiple range test (SAS 1990).

For each measurement of leaf stomatal conductance $\left(\mathrm{gs}_{\mathrm{por}}\right)$, the corresponding modeled value $\mathrm{gS}_{\text {cal }}$ was calculated from the transpiration rate and VPD following the equation of Pearcy et al. (1991):

$$
g s_{c a l}=\frac{E\left\{1-\left[\frac{\left(w_{i}-w_{a}\right)}{2}\right]\right\}}{w_{i}-w_{a}}
$$

where: $\mathrm{E}$ is the transpiration rate as a function of ETE/RG ratio and foliar area and $\mathrm{w}_{\mathrm{i}}$ and $\mathrm{w}_{\mathrm{a}}$ are the values of partial vapor pressure $(\mathrm{kPa})$ in the leaf intercellular spaces and in the atmosphere, respectively. Linear correlation was then performed separately for each species between $\mathrm{gs}_{\text {por }}$ and $\mathrm{gs}_{\mathrm{cal}}$ values.

ANOVA of the eco-physiological plant variables (ET/RG, gs, and $\Delta \mathrm{T}$ ) showed no significant differences among cycles $(p>0.05)$ and no significant interaction between cycle and the two other factors (day and species). Therefore, data from the first cycle are presented here to show the trends of ET/RG, gs, and $\Delta \mathrm{T}$, as representative of the three cycle repetitions. The decrease in container water capacity in treated plants is expressed as the substrate water tension. 


\section{RESULTS}

$N$. oleander showed lower leaf area per plant than the two other species (Fig. 2). ETE $\mathrm{h}_{\mathrm{h}}$ was heavily influenced by the amount of solar radiation. Owing to this reason, water use was calculated as $\mathrm{ET} / \mathrm{RG}$, which is the ratio between the total evapotranspiration along the three hours of measurement and the total amount of incident radiation during the same time (Fig. 3). All species displayed a clear trend toward ET/RG reduction as soil water tension increases, with $N$. oleander always showing significantly higher values than the other two species. $P$. tobira showed intermediate values, and $L$. japonicum showed the lowest ones. N. oleander and P. tobira showed a gradual decrease along the 5 days, whereas L. japonicum remarkably dropped down from the second day, undergoing a gradual further decrease in the remaining days.

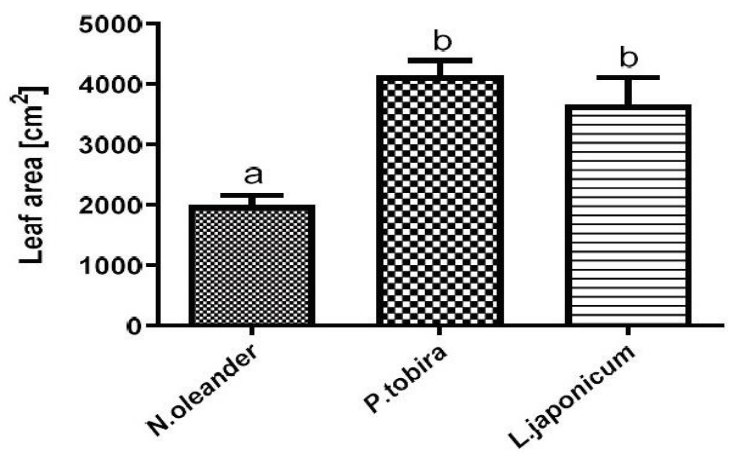

Fig. 2. Leaf area by species. Values marked with the same letter are not statistically different at $p<0.05$, according to Duncan's multiple range test. Error bars were calculated from six measurements (replicates) for each average value

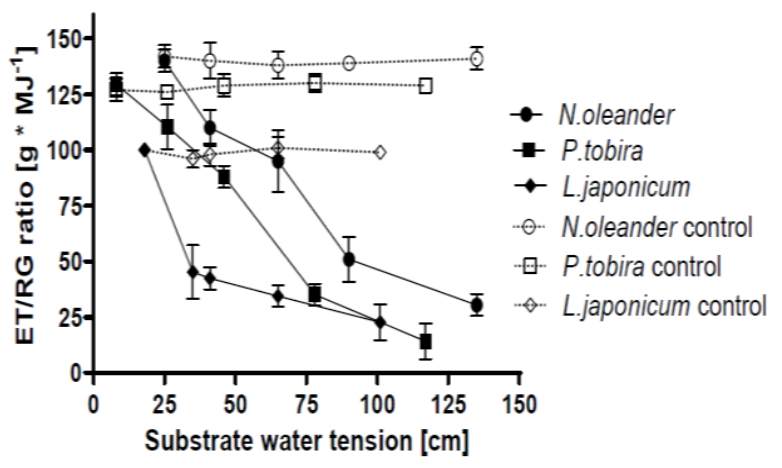

Fig. 3. ET/RG ratio versus substrate water tension Note: See Fig. 2
Stomatal conductance declined for all species as soil water availability diminished (Fig. 4), whereas control plants kept their values at $100 \%$ $\pm 5 \%$ (which means an average fluctuation of \pm $5 \%$ around the first-day-optimal value) during the whole trial (data not shown in the graph). For all the days of experiment, $N$. oleander showed the highest gs values, followed by P. tobira and L. japonicum; gs for $N$. oleander drastically dropped down only at the last day of trial, whereas $P$. tobira showed a gradual reduction and L. japonicum dropped down already between day 2 and day 3 . The differences in stomatal conductance among plants were significant at $95 \%$ for all species in all days, except some overlapping between $P$. tobira and L. japonicum during the first 2 days. On the last day, following the dramatic drop of $N$. oleander, its values became comparable with the ones of P. tobira (Fig. 4). The high level of correlation obtained between the measured gs values and the calculated ones confirms the reliability of the measured data. Three different correlation curves, one for each species, have been identified. The correlation curve for $L$. japonicum meets the origin of axes, with a slope close to one; $N$. oleander has a similar slope but all the measured values are higher than expected; P. tobira displays a markedly lower slope (Fig. 5).

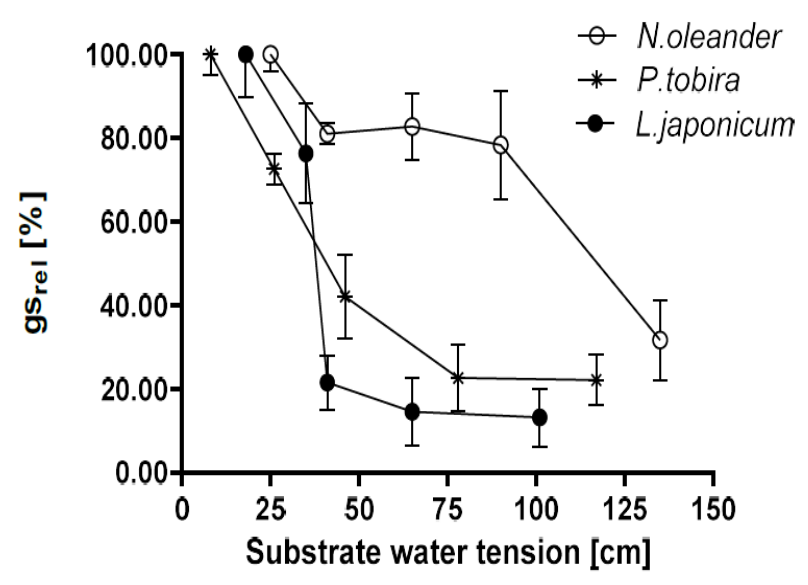

Fig. 4. Relative stomatal conductance $\left(\mathrm{gs}_{\text {rel }}\right)$ versus substrate water tension

Note: See Fig. 2 


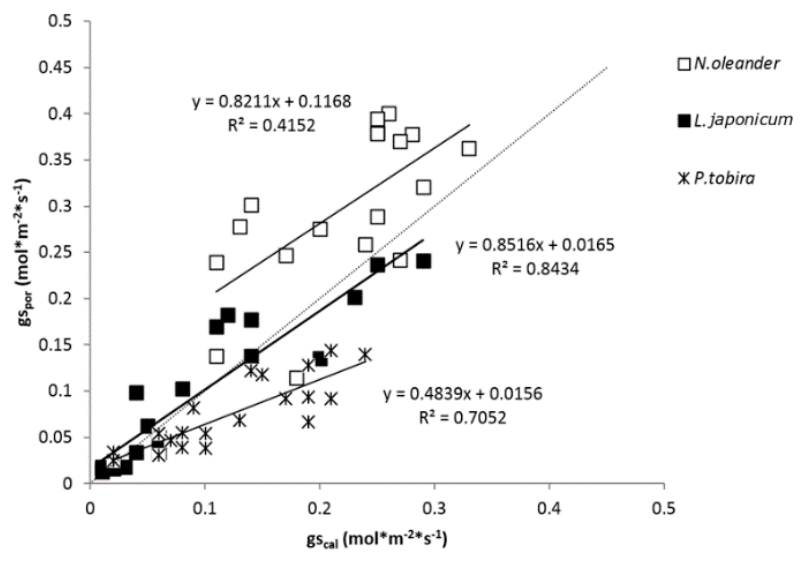

Fig. 5. Linear correlation between measured and calculated stomatal conductance; for each species, a single regression line, with slope and $\mathrm{R}^{2}$, is presented in the graph; the central dotted line represents the ideal $1: 1$ relationship between measured and calculated gs

$\Delta \mathrm{T}\left(\mathrm{T}_{\text {leaf }}-\mathrm{T}_{\mathrm{atm}}\right)$ increased for all species as water stress got more severe (Fig. 6), whereas control plants kept stable values (data not shown in the graph). N. oleander always showed the significantly lowest values, whereas the other two species had higher and similar values, with L. japonicum showing slightly higher ones. The difference between $N$. oleander and the other two species was significant at $95 \%$ during the first 4 days, whereas $P$. tobira and L. japonicum had values of $\Delta \mathrm{T}$ that were more closely associated, even if those of L. japonicum always exceeded the ones of P. tobira.

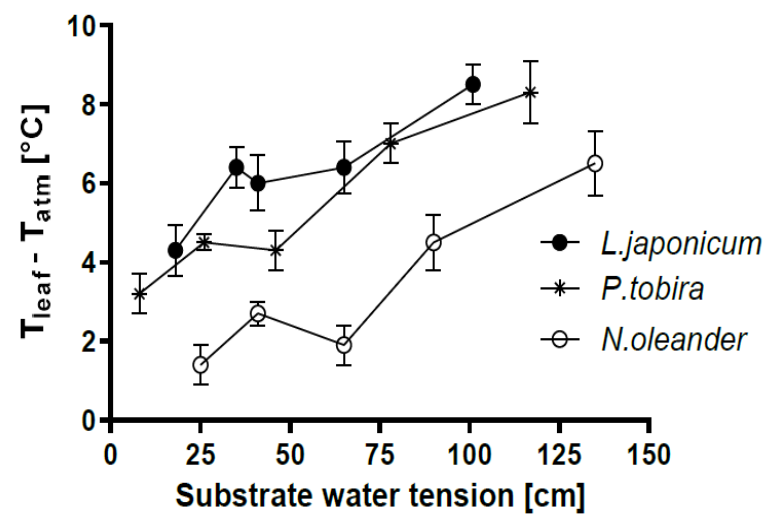

Fig. 6. $\Delta \mathrm{T}$ versus substrate water tension. Note: See Fig. 2

\section{DISCUSSION}

The results point out $N$. oleander as the Mediterranean shrub displaying the greatest tolerance to conditions of increasing water stress. The values of evapotranspiration for $N$. oleander stay at the highest levels during all the stress period, possibly because of the lower leaf area and its different foliar architecture (Badger et al. 1982; Reinert et al. 2013). In fact, $N$. oleander shows a more markedly vertical leaf habit than the other two species, resulting in a lower mutual shading of its leaves, partially counterbalanced by a sharper angle of solar incidence. Moreover, the lower leaf area index of $N$. oleander is likely to be associated with a higher contribution of evaporation from the substrate to the total evapotranspiration (Allen 1998; Yan et al. 2012).

This phenomenon is also explained by the capacity of $N$. oleander of maintaining higher levels of stomatal gas exchange despite the increasing drought conditions. In fact, absolute gs values of $N$. oleander were the highest during the whole trial, even on the last day when they decreased sharply, consistent with the observations of Mugnai et al. (1999). Relative gs values show an even stronger trend, because, at the end of the trial, $N$. oleander stays at a $40 \%$ of its maximum gas exchange capacity, whereas the other two species drop down to a 20\% and earlier than $N$. oleander. Concurrent higher surface evaporation from $N$. oleander substrate, likely due to less shading from lower leaf area, apparently led to more negative substrate water tension increasing more rapidly over the study period, despite regular re-watering, than the other two species. Finally, linear correlation between measured and calculated gs clearly shows that $N$. oleander systematically gives higher scores of stomatal conductance than the ones predicted by the equation.

The similar leaf areas for P. tobira and L. japonicum exclude that differences in evapotranspiration between the two may be due to significant differences in evaporation from the substrate. 
The higher ETE/RG for P. tobira, therefore, suggests that it maintains higher levels of foliar transpiration than $L$. japonicum in conditions of water stress, which is precisely confirmed by the evolution of their gs values along time. The greater sensitivity of $L$. japonicum to water stress may be due to two reasons: gas exchange levels starting initially from lower values, which decreases rapidly with water stress onset. These observations suggest a more isohydric behavior of $L$. japonicum toward drought: the stomata close as soon as the water stress starts to manifest. This behavior is associated with lower risks of hydraulic failure and also reduced gas exchange and carbon uptake and is typical of plants that are defined "drought avoiders" (Tardieu \& Simonneau 1998).

On the other side, the hydraulic behavior of $N$. oleander suggests anisohydric behavior of ostensibly drought-tolerant plants, which maintain gas exchange at the cost of more negative internal water potentials and risk of hydraulic failure and embolisms (Sperry \& Tyree 1988; Sade et al. 2012). For this reason, anisohydric plants usually have stronger vascular structures and better protoplasmic and biochemical stability (Demmig et al. 1988; Vilagrosa et al. 2010).

The increase in $\Delta \mathrm{T}$ from day 1 to day 5 is a typical consequence of reduced foliar transpiration because of stomatal closure from water stress, which reduces evaporative cooling and so leaf temperature rises (Mugnai 2004; Zuccarini et al. 2011). Low $\mathrm{T}_{\text {leaf }}-\mathrm{T}_{\text {atm }}$ in $N$. oleander during the study indicates greater evaporative cooling from transpiration, which directly reflects its higher rates of stomatal transpiration in comparison with the other two species.

Few studies have reported on hydraulic behavior of N. oleander, P. tobira, and/or L. japonicum under water stress, and they were not focused on interspecific comparisons. In this sense, this work is among the few ones reporting on differences in hydraulic behavior among Mediterranean shrubs that can improve their water management in nursery production.
Björkman et al. (1980) already showed gas exchange rates of $N$. oleander decreased with water stress and suggested that effects of water stress and high irradiation may be interrelated, leading to inactivation of PSII (Björkman \& Powles 1984). Later, Demmig et al. (1988) demonstrated in N. oleander, high capacity of its leaves to create foliar zeaxanthin under water and light stress, which protects photosystems from damage through promotion of radiation less dissipation of excess energy, possibly explaining greater drought tolerance in $N$. oleander and also from a biochemical point of view.

This study suggests that $N$. oleander tolerates greater drought stress through anisohydric behavior, which maintains gas exchange at lower substrate water potentials. $L$. japonicum conversely appears to show isohydric behavior in rapidly reducing gas exchange at the onset of water stress, whereas $P$. tobira has an intermediate response.

The present data point out $N$. oleander as the most efficient choice for landscape use in environments subject to recurring situations of water scarcity and, at the same time, they provide useful information for a more focused irrigation management of these Mediterranean shrubs for the plant nursery industry.

\section{Acknowledgments}

Alejandro Galindo acknowledges the financial support received from Ramón Areces Foundation and Universidad de Sevilla (VI PPIT-US).

\section{REFERENCES}

Allen R.G., Pereira L.S., Raes D., Smith M. 1998. Crop evapotranspiration. Guidelines for computing crop water requirements. Food and Agriculture Organization of the United Nations, Rome, Italy. FAO Irrigation and Drainage 56, $15 \mathrm{p}$.

Badger M.R., Björkman O., Armond P.A. 1982. An analysis of photosynthetic response and adaptation to temperature in higher plants: temperature acclimation in the desert evergreen Nerium oleander L. Plant, Cell and Environment 5: 85-99. DOI: 10.1111/1365-3040.ep11587620. 
Björkman O., Downton W.J.S., Mooney H.A. 1980. Response and adaptation to water stress in Nerium oleander. Carnegie Institution of Washington. Year Book 79: 150-157.

Björkman O., Powles S.B. 1984. Inhibition of photosynthetic reactions under water stress: inter-action with light level. Planta 161: 490-504. DOI: 10.1007/bf00407081.

Cassel D.K., Klute A. 1986. Water Potential: Tensiometry. In: Klute A. (Ed.), Methods of Soil Analysis, Part 1: Physical and Mineralogical Methods, 2nd ed. Agronomy 9(1): 563-596. DOI: 10.2136/sssabookser5.1.2ed.c23.

Demmig B., Winter K., Krüger A., Czygan F.C. 1988. Zeaxanthin and the heat dissipation of excess light energy in Nerium oleander exposed to a combination of high light and water stress. Plant Physiology 87: 17-24. DOI: 10.1104/pp.87.1.17.

Denys S., Rollin C., Guillot F., Baroudi H. 2006. In-situ phytoremediation of PAHs contaminated soils following a bioremediation treatment. Water, Air, and Soil Pollution: Focus 6: 299-315. DOI: 10.1007/s11267-005-9024-z.

Di Lorenzo R., Pisciotta A., Santamaria P., Scariot V. 2013. From soil to soil-less in horticulture: quality and typicity. Italian Journal of Agronomy 8: 255260. DOI: 10.4081/ija.2013.e30.

Gu Z., Qi Z., Burghate R., Yuan S., Jiao X., Xu J. 2020. Irrigation scheduling approaches and applications: A review. Journal of Irrigation and Drainage Engineering 146; 04020007; 15 p. DOI: 10.1061/(asce)ir.1943-4774.0001464.

Hoekstra A.Y., Chapagain A.K. 2007. Water footprints of nations: water use by people as a function of their consumption pattern. Water Resources Management 21: 35-48. DOI: 10.1007/s11269-006-9039-x.

IEEE 2010. The coming clash between water and energy. The Institute of Electrical and Electronic Engineers, USA. IEEE Spectrum 47: 22-23.

Incrocci L., Marzialetti P., Incrocci G., Di Vita A., Balendonck J., Bibbiani C. et al. 2014. Substrate water status and evapotranspiration irrigation scheduling in heterogenous container nursery crops. Agricultural Water Management 131: 3040. DOI: 10.1016/j.agwat.2013.09.004.

Jones H.G. 2004. Irrigation scheduling: advantages and pitfalls of plant-based methods. Journal of Experimental Botany 55: 2427-2436. DOI: 10.1093/jxb/erh213.
Knox G.W. 1989. Water use and average growth index of five species of container grown woody landscape plants. Journal of Environmental Horticulture 7: 136-139. DOI: 10.24266/0738-2898-7.4.136.

Mugnai S. 2004. Elementi di Ecofisiologia vegetale. In: Pardossi A., Incrocci L., Marzialetti P. (Eds.), Uso razionale delle risorse nel florovivaismo: l'acqua. Quaderno ARSIA 5: 35-47. [in Italian]

Mugnai S., Tognoni F., Serra G. 1999. Water consumption and growth in nine container-grown ornamental species. Agricoltura Mediterranea 129: 143-147.

Pearcy R.W., Schulze E.D., Zimmermann R. 1991. Measurement of transpiration and leaf conductance. In: Pearcy R.W., Ehleringer J., Mooney H.A., Rundel P.W. (Eds.), Plant Physio-logical Ecology, UK, pp. 137-160. DOI: 10.1007/978-94-009-2221-1_8.

Postel S.L. 2000. Entering an era of water scarcity: The challenges ahead. Ecological Applications 10: 941-948. DOI: 10.1890/10510761(2000)010[0941:eaeows]2.0.co;2.

Reinert F., Leal-Costa M.V., Junqueira N.E., Tavares E.S. 2013. Are sun- and shade-type anatomy required for the acclimation of Neoregelia cruenta? Anais da Academia Brasileira de Ciências 85: 561573. DOI: 10.1590/s0001-37652013005000034.

Ristvey A.G., Lea-Cox J.D., Ross D.S. 2004. Nutrient uptake, partitioning and leaching losses from container-nursery production systems. Acta Horticulturae 630: 321-328. DOI: 10.17660/actahortic.2004.630.40.

Sade N., Gebremedhin A., Moshelion M. 2012. Risk-taking plants: Anisohydric behavior as a stress-resistance trait. Plant Signaling and Behavior 7: 767770. DOI: $10.4161 /$ psb.20505.

Sample J. 2009. World faces "perfect storm" of problems by 2030 , chief scientist to warn. Retrieved September 06, 2010 from the Guardian, UK. http://bit.ly/39qAMmy

SAS 1990. SAS User's Guide: Basics. SAS Institute, Cary, USA.

Savé R., Castell C., Terradas J. 1999. Gas exchange and water relations. In: Rodà F., Retana J., Gracia C.A., Bellot J. (Eds.), Ecology of Mediterranean Evergreen Oak Forests. Springer, Ecological Studies 137: 135-147. DOI: 10.1007/978-3-642-58618-7_10.

Schuch U.K., Burger D.W. 1997. Water use and crop coefficients of woody ornamentals in containers. Journal of the American Society for Horticultural Science 122: 727-734. DOI: 10.21273/jashs.122.5.727. 
Sperry J.S., Tyree M.T. 1988. Mechanism of water stress-induced xylem embolism. Plant Physiology 88: 581-587. DOI: 10.1104/pp.88.3.581.

Stewart-Wade S.M. 2011. Plant pathogens in recycled irrigation water in commercial plant nurseries and greenhouses: their detection and management. Irrigation Science 29: 267-297. DOI: 10.1007/s00271011-0285-1.

Styles J.M., Raupach M.R., Farquhar G.D., Kolle O., Lawton K.A., Brand W.A. et al. 2002. Soil and canopy $\mathrm{CO}_{2}, 13 \mathrm{CO}_{2}, \mathrm{H}_{2} \mathrm{O}$ and sensible heat flux partitions in a forest canopy inferred from concentration measurements. Tellus 54B: 655-676. DOI: 10.3402/tellusb.v54i5.16708.

Sun Y., Zhou Q., Xu Y., Wang L., Liang X. 2011. Phytoremediation for co-contaminated soils of benzo[a]pyrene $(\mathrm{B}[\mathrm{a}] \mathrm{P})$ and heavy metals using ornamental plant Tagetes patula. Journal of Hazardous Materials 186: 2075-2082. DOI: 10.1016/j.jhazmat.2010.12.116.

Tardieu F., Simonneau T. 1998. Variability among species of stomatal control under fluctuating soil water status and evaporative demand: modelling isohydric and anisohydric behaviours. Journal of Experimental Botany 49: 419-432. DOI: 10.1093/jxb/49.special_issue.419.
Trombetta A. et al. 1992. Metodi di analisi dei compost. Determinazioni chimiche, fisiche, biologiche e microbiologiche. DIVAPRA, IPLA, ARPA. Collana Ambiente, Regione Piemonte, Assessorato all'Ambiente, Italy, 187 p. [in Italian]

UNEP 2007. Global Environment Outlook. GEO4: environment for development. United Nations Environment Programme, Valletta, Malta.

Vilagrosa A., Morales F., Abadía A., Bellot J., Cochard H., Gil-Pelegrin E. 2010. Are symplast tolerance to intense drought conditions and xylem vulnerability to cavitation coordinated? An integrated analysis of photosynthetic, hydraulic and leaf level processes in two Mediterranean drought-resistant species. Environmental and Experimental Botany 69: 233242. DOI: 10.1016/j.envexpbot.2010.04.013.

Yan H., Wang S.Q., Billesbach D., Oechel W., Zhang J.H., Meyers T. et al. 2012. Global estimation of evapotranspiration using a leaf area index-based surface energy and water balance model. Remote Sensing of Environment 124: 581-595. DOI: 10.1016/j.rse.2012.06.004.

Zuccarini P., Ciurli A., Alpi A., Hegedüšová K. 2011. Hydraulic and chemical mechanisms in the response of Pinus pinaster Ait. to conditions of water stress. Ekológia (Bratislava) 30: 422-437. DOI: 10.4149/ekol_2011_04_422. 